\title{
Photosynthetic Alterations of Virus Infected Plants*
}

\author{
A. ALMÁSI ${ }^{1}$, A. HARSÁNYI ${ }^{1}$ and R. GÁBORJÁNYI ${ }^{2}$ \\ ${ }^{1}$ Plant Protection Institute, Hungarian Academy of Sciences, \\ H-1525 Budapest, P.O. Box 102, Hungary \\ ${ }^{2}$ Veszprém University, Georgikon Faculty of Agricultural Sciences, \\ H-8361 Keszthely, P.O. Box 71, Hungary
}

\begin{abstract}
The most obvious symptom of systemic virus infection is the mosaic pattern of the leaves. Yellowing, chlorosis is also frequent and characteristic sign of the altered photosynthetic activity. Virus infection effects photosynthesis in a complex manner, depending on the particular host-virus combination. The symptoms are basically different in the incompatible or the compatible host-virus interaction.
\end{abstract}

Keywords: Photosynthesis, virus infection, biotic stress.

\section{Photosynthetic changes in incompatible host-virus interaction}

Virus infection often causes local lesions in resistant plants. The development of local lesions in hypersensitive reaction (HR) was described in details by electron microscopy, based on the time course of the appearance of symptoms (Weintraub and Ragetli, 1964). The ultrastructure of the lesion and the surrounding cell layers and the role of the active zone in the localisation of the infection was highlighted (Israel and Ross, 1967).

In tobacco mosaic tobamovirus (TMV) infected N. glutinosa leaves the size and number of the starch grains increased in the chloroplasts following the infection (Weintraub and Ragetli, 1964). One day after the infection plasmolysis occurred, and first the cytoplasm and later the chloroplast membranes completely disappeared. In the remains of the chloroplasts large vesicles were formed, the number of mitochondria increased and their structure changed. Finally the whole cell structure collapsed and its content disintegrated. All these alterations were consequences of the loss of osmotic regulation, and have been related to the so-called 'starch-lesions' described by Holmes (1931).

Israel and Ross (1967) have studied the cells of necrotic lesions, the tissues in the direct vicinity (active zone), and the outer visually unaffected cells. The cells in the lesions contained very few cell organelles; starch grains, disrupted thylakoid membranes, displaced ribosomes. The cells of the active zone showed increased metabolic activity. The number of chloroplasts increased due to their frequent division. Similar alterations were described in the case of another host plant (Phaseolus vulgaris var. Pinto) following TMV infection (Spencer and Kimmins, 1971).

The phenomena of chloroplast swelling and abruption in HR were examined by da Graça and Martin (1975) in TMV infected N. tabacum cv. "Samsun NN" plants. The primary symptom of HR was the change in the permeability of membranes. The oxidative burst, the increase in peroxidase and lipoxigenase activity lead to the brake up of membranes (Weststeijn, 1978; Dhindsa et al., 1981; Sutherland, 1991). 
In the lesions of potato virus $S$ carlavirus (PVS) infected Chenopodium quinoa Shukla and Hiruki (1975) often found cytoplasmic invaginations containing ribosomes in the chloroplasts and in the stroma, the accumulation of fitoferritin, which was not specific to the PVS infection, because other viruses or certain stress factors cause the same symptoms (Rana et al., 1989).

\section{Photosynthetic changes in compatible host-virus interaction}

For the synthesis of virions the parasite uses the metabolites and energy of the host plant, which are produced in the course of photosynthesis. It is evident that the physiological processes of the virus and the plant are linked in complex ways, the structure and the function of the chloroplasts are disturbed (Zaitlin and Hull, 1987).

\section{Changes in the ultrastructure of chloroplasts}

The chlorosis of leaf tissues in the compatible host parasite interactions can be traced back to different causes. The number, size or chlorophyll content of the chloroplasts may decrease (Tu et al., 1967). Their shape, inner membrane structure may alter to some degrees, some of their metabolites may accumulate, etc. (Goodman et al., 1986). Often the starch grains enlarge, or accumulate for example in the case of the cauliflower mosaic caulimovirus (CaMV) infected cabbage plants (Conti et al., 1972). In several other combinations the appearance of large starch grains, the disappearance of thylakoid, stroma and grana membranes and the increase of plastoglobuli (Koiwa et al., 1989; Russo and Martelli, 1981) is similar to the chloroplast to chromoplast transformation (Tomlinson and Webb, 1977; Schuchalter-Eicke and Jeske, 1983), or to the phenomena of senescence. This idea is underlined by the fact that the application of a citokinin type substance (karbendazim) in the leaves of lettuce infected with beet western yellows betaluteovirus, (BWYV) caused the suppression of symptoms (Tomlinson and Webb, 1977). SchuchalterEicke and Jeske (1983) studied the seasonal rhythm of chloroplast symptoms in abutilon mosaic bigeminivirus (AbMV) infected Abutilon sp. plants, which can also be correlated with senescence. The microscopic changes reflected the influence of light intensity and season on the lighter/darker mosaic pattern: in summer the inner membrane structure almost completely disintegrated, showed vesicular, tubular or myelin-like structure, while in winter prolamellar body-like structures developed in the plastids, which resulted in the reorganisation of grana. According to the authors the virus regulates the chloroplast/chromoplast transition by switching the organelle's coded 'program' on and off.

The effect of virus infection on the development and differentiation of plastids was summarised in the study of cucumber mosaic cucumovirus (CMV) infected tobacco leaves (Ehara and Misawa, 1975). Depending on the time of inoculation, the plastids differentiated irregularly. The ratio of degenerated plastids changed with the time course of symptom development. The myelin-like or tubular structure was not formed by the disruption of the existing lamellae, but by their irregular development. In the case of BSMV infected etiolated barley seedlings we reported not only the accelerated senescence but the inhibition of chlorophyll biosynthesis (Almási et al., 2000). 
The presence of vesicles within or attached to plastids was reported by Hibino et al. (1974a,b). In tobacco leaves infected with TMV U5 strain it was proved by autoradiography that the chloroplasts do not take part in the biosynthesis of virions, which means that the vesicles do not play any role in virus replication (Betto et al., 1972). This was also regarded as a secondary effect in tomato spotted wilt tospovirus (TSWV) infected tobacco leaves (Mohamed, 1973).

In contrast, the replication of tymovirus genus is related to the chloroplasts. The swelling of the chloroplasts and the formation of small vesicles were reported in chinese cabbage infected with turnip yellow mosaic tymovirus (TYMV) (Ushiyama and Matthews, 1970). The plastids became globular, the number of vesicles in the plastids increased and they formed clusters covered by endoplasmic reticulum (ER) from the cytoplasmic side (Hatta and Matthews, 1974). The region between the ER and the plastid envelope became electronlucent, and the ER disappeared. Then the plastids clustered and virions were observable in the zone between the plastids. In the vesicles of the inner surface of the envelope, double stranded nucleic acids were visible, which proved to be the replicative form of viral RNA. Based on these results it was supposed that these vesicles serve as sites of viral replication, then the viral RNA translocates into the cytoplasm where the viral proteins are synthesised, and finally the assembly of the virions is completed. These peripheral vesicles open into the cytoplasm with short necks (channels) (Matthews, 1977). Similar changes were noted for leaves of wild cucumber (Marah oreganus) infected with wild cucumber mosaic tymovirus (WCMV) (Allen, 1971), where virions were also present in the stroma as well as in the cytoplasmic invaginations.

Abnormal vesiculated plastids were observed in susceptible host plants (barley, wheat) infected with barley stripe mosaic hordeivirus (BSMV). The grana of the deformed, swollen plastids had an unusual structure. Between the inner and outer membranes of the envelope single membrane bound vesicles were apparent (Carroll, 1970; Jackson et al., 1989). In the peripheral vesicles of the chloroplasts Lin and Langenberg (1985) had observed the replicative form of viral dsRNA, so the plastids could be related to virus synthesis. Symptom development was categorised into timecourse stages, such as primary, secondary acute (inoculated leaves) and chronic phase (systemic leaves) (Mc Kinney and Greeley, 1965). In yellow tissues of the primary acute phase plastids were often found with translucent stroma, which lacked ribosomes. Their thylakoids were irregularly twisted, forming a tubular reticulum with enlarged grana. In the secondary acute phase the degradation of plastids continued until the death of the cells. The young plastids of the chronic phase contained irregular thylakoids, small, few lamellar grana, which sometimes vesiculated (Mc Mullen et al., 1978). The reason for the development of a mosaic pattern is the clustered layout of the chloroplasts that have been damaged to various degrees. Chalcroft and Matthews (1967) had thought that in the dividing cells of chinese cabbage infected with TYMV the spontaneously mutating virus strains of different pathogenicity end up in different daughter cells. The symptom development was regarded by Gardner (1967) as the result of the different tolerance level of the host cells. Mc Mullen et al. (1978) had proposed that the virus regulates the phenotype of the plastids through the nuclear or plastidial genom. In contrast, in the case of systemic infection of barley yellow mosaic bymovirus (BYMV) there was a linear correlation between the virus concentration and symptom severity (Huth et al., 1984). 
In certain host-parasite interactions the presence of unusually large grana ("supergrana") had been observed (Šarič and Wrischer, 1975; Sjolund and Smith, 1974). By freeze fracture method replica were made from the granal surface, and based on the number and size of the contained particles the damage of photosystem II (PSII) was determined.

\section{Changes in the chlorophyll protein complexes and chloroplast proteins}

Virus infected monocotyledons (e.g. barley infected with BSMV or WSMV) contained reduced amount of chlorophyll protein complexes compared to the healthy controls (White and Brakke, 1983). Koiwa et al. (1992) supposed that virus infection inhibits PSII activity selectively by the decomposition of light harvesting antenna complex of PSII (LHCII), based on their findings on the ratio of particles in the surface of the thylakoid membranes in tomato plants infected with TMV. Similarly, Eupatorium makinoi leaves infected with tobacco leaf curl geminivirus (TLCV) the amount of LHCII decreased in the chloroplasts (Funayama et al., 1997a,b). The chlorophyll protein complexes and the protein content of the thylakoids in peanut infected with peanut green mosaic potyvirus (PGMV) had been altered in parallel to the symptom development (Naidu et al., 1984a). The complexes reduced to the greatest extent were identified by SDS polyacrylamid gel electrophoresis (PAGE). All these components belonged to PSII and LHCII: namely the $47 \mathrm{kD}$ chlorophyll protein, the $23 \mathrm{kD}$ LHCII chlorophyll protein and the $\alpha-, \beta$-subunits of the ATP synthase). There were no significant differences in PSI reaction centre, while in LHCI the amount of the chlorophyll protein complexes slightly increased. In our experiments we detected the loss of chlorophyll protein complexes of both photosystems (i.e. PSII and PSI) (unpublished data). In TYMV infected chinese cabbage chloroplasts the antenna complexes (LHCII and LHCI) decreased to the greatest extent, while in TSWV infected Nicotiana benthamiana chloroplasts the complexes belonging to the reaction centers (PSII CC and PSI RC) were mostly affected. Later in a more sophisticated system (by improved PAGE techniques) Naidu et al. (1986) detected the loss of 14, 18, 19, 23 and $33 \mathrm{kD}$ proteins. The 23 and $33 \mathrm{kD}$ proteins belong to the oxygen evolving complex (OEC) of PSII, and their changes showed a good correlation with the decreased efficiency of $\mathrm{O}_{2}$ evolution. Takahashi et al. (1991) determined the 22, 23 and $24 \mathrm{kD}$ proteins of OEC from tobacco leaves infected with CMV separately by using two-dimensional gels. They supposed these three proteins to be the products of the same small multigen family. The amount of the 22 and $23 \mathrm{kD}$ proteins had started to decrease at the time of the appearance of chlorotic spots, while the changes in the amount of the $24 \mathrm{kD}$ and $33 \mathrm{kD}$ proteins which induce more severe symptoms started only after that (Takahashi and Ehara, 1992). To sum up all these results the authors proposed, that the environmental factors do not induce or suppress the distinct elements of certain gene families in the same manner or at the same time. The inhibition of OEC is not a secondary consequence of the symptom development, but it is rather connected with the primary molecular processes of the infection.

Among the stroma proteins the loss of the small subunit of ribulose-1,5-bisphosphate-carboxylase-oxygenase (Rubisco) enzyme was reported in the chlorotic tissues of cucumber plants infected with CMV (Ziemieczki and Wood, 1975), and in the chloroplasts of tobacco leaves infected with TSWV together with the reduced level of $70 \mathrm{~S}$ ribosomes (Mohamed and Randles, 1972). 
In parallel to the decrease in chlorophyll content a significant increase was measured in the enzyme activity of the chlorophyllase which catalyses the dephytilisation of the chlorophyll molecules (Bailiss, 1970). It was interpreted as the consequence of the release of chlorophyllase enzyme bound to the chloroplast inner membrane following the disrupture of the chloroplasts.

\section{Effect of virus infection on the photosynthetic electron transport}

Chlorotic leaves of tobacco infected with tobacco etch potyvirus (TEV) showed a decreased level of photosynthetic activity compared to control plants. The light reaction (Hill reaction and photophosphorylation) of isolated chloroplasts showed similar efficiency (Hopkins and Hampton, 1969a). Hodgson et al. (1989) described the selective inhibition of PSII in spinach infected with TMV. The fluorescence kinetic parameters measured in the thylakoids of mosaic pattern leaves showed considerable deviance. The $\mathrm{Fv} / \mathrm{Fm}$ ratio (the potential photosynthetic efficiency parameter of PSII) significantly decreased to the values of the uninfected DCMU treated leaves. The $\mathrm{O}_{2}$-evolution of thylakoids was lower than in the healthy control, and this was the primary result of PSII inhibition. The PSI electrontransport was unaffected. The chlorophyll a/b ratio slightly decreased. From the above results the authors concluded that in the symptomatic leaves of virus-infected plants the cyclic phosphorylation and ATP synthesis dominates over the non-cyclic electrontransport that results in $\mathrm{NADP}^{+}$reduction. In TYMV inoculated leaves of chinese cabbage both the cyclic and the non-cyclic phosphorylation is more intensive during the period of active virus synthesis (Goffeau and Bové, 1965). When the virus concentration reaches its maximum in the plant, in the chloroplasts of systemically infected leaves the previous activity is depressed, the amount of ATP is significantly lower than in the control. Therefore Goffeau and Bové (1965) considered that the ATP formed by photosynthesis as energy source is directly used for the virus protein and nucleic acid synthesis. Kano (1985) drew the same conclusion. Net photosynthesis, chlorophyll content and the ratio of chlorophyll $\mathrm{a} / \mathrm{b}$ decreased in peanut leaves infected with PGMV (Naidu et al., 1984b). The loss of PSII activity was more pronounced than that of PSI. Both cyclic and non-cyclic photophosphorylation was inhibited, although still functioning.

Funayama et al. (1997b) found higher chlorophyll a/b ratio in the leaves of a geminivirus infected Eupatorium makinoi. The net photosynthesis measured at saturating light intensity $(\mathrm{Pm})$ and Fv/Fm showed lower values with the increasing Fm. In virus infected plants the proportion of the $\beta$ reaction centers that have smaller antennae related to the all PSII centers proved to be much higher than in the healthy plants. Energy distribution balance between PSII and PSI broke down (Funayama et al., 1998).

In dark-adapted leaves of $N$. benthamiana plants infected with PMMV-S, PMMV-I or with the hybrid viruses constructed of them. Rahoutei et al. (1998) detected a considerable increase of the non-photochemical quenching (NPQ) while photochemical quenching $(\mathrm{qP})$ decreased. These changes show the diminished ability for energy capture of PSII reaction centers in virus infected plants, and they function as photoprotective mechanisms to irradiate excess energy (Barón et al., 1995; Rahoutei et al., 1998). 
In the leaves of Abutilon striatum plants infected with AbMV simultaneously with the symptom development the Fv/Fm slightly decreased compared to the controls while the drop of Fo was considerable (Osmond et al., 1998). In the orange coloured leaf tissue and in the 'green islands' surrounded by veins NPQ had been continuously reduced or stopped. The disability of the chloroplasts to emit/dissipate excitation energy neither by NPQ, pH-dependent quenching nor by thermal irradiation, leads to the loss of more chlorophylls and to the appearance of more severe symptoms.

Peterson and Aylor (1995) studied the spatial distribution of fluorescence in leaves of plants under different biotic stresses in vivo by using a new method, the fluorescence imaging. The transformation of chlorosis to mosaic pattern at high light intensity coincided with the loss of fluorescence.

\section{Effect of virus infection on $\mathrm{CO}_{2}$-fixation and on some biosynthetic processes}

In several virus-host interactions the disturbances of $\mathrm{CO}_{2}$-fixation and of related metabolic ways, or the alteration in ratio of certain products was reported. At the early stage of systemic TMV infection (virus replication) more $\mathrm{CO}_{2}$ molecules assimilated by the photosynthetic processes (Doke and Hirai, 1970a). As the infection had been progressed this tendency inverted: $\mathrm{CO}_{2}$-uptake was decreasing in the infected tissues (Doke and Hirai, 1970b; Hunter and Peat, 1973). The same changes as well as the increase of respiration were observed in tobacco leaves infected with tobacco etch potyvirus (TEV) (Hopkins and Hampton, 1969b). The enzyme activity of phosphoenol-pyruvate-carboxylase (PEP-carboxylase) increased in the leaves of chinese cabbage infected with TYMV (Bedbrook and Matthews, 1972). In contrast, in tobacco leaves infected with TSWV activity loss of PEP-carboxylase was measured (Mohamed, 1973), and it was explained as the early senescence induced by the virus infection.

In virus infected plants amino acids translocated from the chloroplasts to the cytoplasm, which means that $\mathrm{CO}_{2}$ built into amino acids instead of free sugars (Magyarosy et al., 1973; Platt et al., 1979). The primary metabolites of the photosynthetic pathway transformed into glucose, amino acids or organic acids, which are not able to translocate from the site of their production (Bedbrook and Matthews, 1973). Sugar and starch accumulation was the result of the disturbed translocation. Therefore metabolites like soluble carbohydrate cannot get from the healthy leaves into the infected ones (Tu, 1978; Mandahar and Garg, 1972). Tomato yellow mosaic geminivirus (ToYMV) primarily replicates in the phloem cells of tomato plants causing their pathologic alterations (Leal and Lastra, 1984). This way, virus infection inhibits the translocation of assimilates. But in the case of red clover mottle comovirus (RCMV), the distribution is not restricted to the phloem of the host plant. Photosynthetic metabolites transformed into starch, amino acids and organic acids, too (Técsi et al., 1992). Hence starch accumulation was observed in the cells in which virus did not replicate, therefore it could not be a direct or specific effect, but secondary consequences of the upset balance between the sink and source.

Disturbances in the translocation of the photosynthetic assimilates may be related to the synthesis of viral movement protein (MP) (Lucas et al., 1993; Olesinski et al., 1995; Ding et al., 1996, 1998; Helms and Wardlaw, 1977; Herbers et al., 1997). Roberts and Wood (1982) analysed the possible relationship between chlorosis, virus replication 
and starch accumulation in two pathogenically different CMV strains. They concluded that the severity of chlorotic symptoms does not depend on the virus content. In the leaves of tobacco infected with the strain inducing strong chlorosis they could not detect more starch than in the control leaves, while in the leaves showing milder symptoms typical pattern of starch accumulation appeared. On the primary leaves of squash cotyledons susceptible to CMV infection chlorotic lesions developed (Cohen and Loebenstein, 1975) while on the mature leaves yellow mosaic pattern occurred systemically, which contained starch grains (Técsi et al., 1994). These starch lesions could be divided into four concentric parts based on their structure. In the middle there were cells showing high photosynthetic activity, with a great amount of starch. The next surrounding zone contained mostly starch-free cells with lower photosynthetic activity, then a transitional zone, and the most outer zone contained cells with higher photosynthetic activity, but without a considerable amount of starch. Starch accumulation was the direct effect of the increased photosynthetic activity rather than the result of the metabolite translocation from the non-infected tissues. In the cells of the lesions the physiological changes were connected to the virus replication, which was supported by the fact that positive and negative sense viral RNA accumulated in the first front line of the infection (Técsi et al., 1996). In the zones of the lesions the activity of the enzymes of the oxidative pentose-phosphate pathway and of the NADPdependent malate dehydrogenase enzyme grew (Técsi et al., 1996). The spatial distribution of chlorotic symptoms correlated with the increase of glycolysis and respiration, and with the loss of the photosynthetic activity and protein synthesis.

\section{Relationship between the virus and/or its product accumulation and the symptom devel- opment}

The build up of TMV virions was proven by ultrathin microscopic slices of tobacco chloroplasts (Esau, 1968), or in the chloroplast stroma of Johnsongrass chlorotic stripe carmovirus (JoCSV) infected Sorghum halepense (Izadpanah et al., 1993). Several authors studied the presence of viruses in the etioplasts of tobacco plants (Pratt, 1969; Honda and Matsui, 1971). Following infection with TMV U5 strain, in the chloroplasts of the susceptible tobacco plants, the size of the observed virions was 1/3 the normal virion length, so the virus-like particles were probably pseudovirions (Shalla et al., 1975). Koiwa et al. (1990) proved the in situ presence of TMV in the chloroplasts by electron microscopic slides. It still remains as a matter debate, what role the individual viral constituents like the coat protein (CP), or the "movement proteins" (MP), or other possibly toxic product of the viral genom, or the viral nucleic acids play in the development of different symptoms.

Reinero and Beachy (1986) have described the accumulation of TMV CP and the correlation between the $\mathrm{CP}$ concentration and the severity of symptoms. The coat protein was primarily attached to the thylakoid membrane. They proposed that the TMV CP was bound to one of the chloroplast proteins. Reinero and Beachy (1989) compared symptoms caused by TMV strains of different pathogenity, and concluded that the impairment of the electron transport was on the reducing site of PSII. The results of Hodgson et al. (1989) also underlined the hypothesis, that the CP directly inhibited PSII by binding 
directly onto it. The 20,40 and $60 \mathrm{kD}$ proteins which appeared with the onset of infection in the thylakoid membranes have been shown by immunological detection to be the oligomer forms of the coat protein. Thus the impairment of the electron transport was directly induced by the CP. Changes in fluorescence kinetics have also been attributed to the attachment of CP to the thylakoids (Balachandran et al. 1994a), and later to the aggregation of chlorophylls in the light harvesting antenna complex of PSII.

From experiments with coat protein mutant viruses it was evident that even though the virion assembly was inhibited by the modification of the coat protein by gene insertion or deletion, it did not block the replication, or the movement from cell to cell and certain systemisation of the infection (Dawson et al., 1988). The mutant viruses replicated and moved within the cells in the form of free RNA. The protein products derived from abnormal $\mathrm{CP}$ genes led to the development of diverse symptoms, but common among them was the appearance of chlorosis. This observation showed that the CP plays an important role in the initiation of the close physiological interaction between the virus and the host plant. In experiments of Banerjee and Zaitlin (1992) with mutant TMV strains and artificially created chimera viruses had shown that a single nucleotide change in the CP gene caused a drastic change in symptoms.

The toxicity of CP was proved by Naderi and Berger (1997) with the use of genetically modified tobacco plants, into which the potato Y potyvirus (PVY) CP gene linked with the transit peptide of the small subunit of Rubisco enzyme was built in, so the virus coat protein was transmitted into the chloroplast. The coat protein like products of the CP mutant TMV strains did not accumulate in the chloroplasts (Lindbeck et al., 1991), however still different symptoms were expressed. According to the authors the $\mathrm{CP}$ excerted its effect on symptom development outside the chloroplast. Slight and severe symptom producing strains of CMV (where CP did not accumulate in the plastids) were compared by Roberts and Wood (1981) based on the rate of CP accumulation. The strain with strong symptoms produced considerably greater concentration of $\mathrm{CP}$ within the cells of the host plant, and there was a direct correlation between the concentration of $\mathrm{CP}$ and the development of symptoms.

Viral RNA was detected within the plastids in the case of several virus infections. The presence of these RNAs may indicate the site of viral synthesis, e.g. in TYMV (Ralph et al., 1971), or in BSMV (Lin and Langenberg, 1985). With regards to the synthesis of potyviruses it was possible that the replication takes place within the plastids (Mayhew and Ford, 1974; Teakle and Pares, 1977; Gadh and Hari, 1986). During the systemic infection of PVY it was also shown that the CP, the helper component (HC) and the PVY RNA was present in the plastids (Gunasinghe and Berger, 1991). The coat protein was present mainly in the thylakoid fraction rather than in the stroma. It is still an open question whether the gene products of the virus RNA are translated in the chloroplasts or are transported from the cytoplasm. TMV L-RNA devoid of coat protein was detected inside the chloroplasts, while S-RNA was not found (Schoelz and Zaitlin, 1989). The authors therefore doubted the translocation of TMV CP into the plastids, but supposed that the protein is translated by the chloroplast ribosomes from the TMV RNA. An answer to this hypothesis was attempted by Banerjee and Zaitlin (1992), who had 
investigated the in vitro mobility of the TMV CP into isolated intact chloroplasts. TMV CP quickly mobilised into the chloroplasts, without the preliminary splitting of any transit peptide as was previously observed in vitro by Chua and Schmidt (1978) when the smaller subunit of the Rubisco enzyme mobilised into the chloroplast. The process also took place in the absence of ATP, so unlike active transport it does not need an energy source.

The parallel inoculation with (CMV Y) satellite RNA and CMV strain with weak pathogenity produced the modification of symptoms in tobacco (Masuta et al., 1993). The authors considered that the chlorosis induced by the satellite RNA was a result of the inhibition of de novo chlorophyll synthesis, because the symptoms were solely expressed in the newly developing leaves.

In the inhibition of photosynthesis and the modification of symptoms not only the coat protein might play a role, but also the different virus MP-s (Helms and Wardlaw, 1977; Ding et al., 1998). TMV MP producing transgenic tobacco plants were made in which the photosynthetic activity was lowered and NPQ was higher. The rate of electron transport decreased. Based on the different chlorophyll fluorescence parameters it seemed likely that the TMV MP did not directly effect any step of the electron transport chain, but caused the specific inhibition of phosphate uptake (Wolf and Millatiner, 2000). The transport of carbon metabolism and $\mathrm{CO}_{2}$ fixation products into the distal parts of the plant were impaired in these plants (Lucas et al., 1993; Olesinski et al., 1995). The continuous production of TMV MP affected the plasmodesma size dependent permeability (SEL) of the palisade layer in the mesophyll. It was shown that the product transport through the simplast, the distribution of photosynthetic assimilates and the distal transport processes in the phloem were also affected. In the same experiment the build up in the concentration of saccharose, glucose and fructose as a negative feedback blocked the triose phosphate translocator of the chloroplast. Thus stimulated the starch synthesis and storage, which lead to a net reduction in photosynthesis. The TMV MP therefore affected the photosynthetic activity of plants in a complex way.

Herbers et al. (1997) compared the effect of the potato leafroll polerovirus (PLRV) MP with the findings of TMV MP to see how general these changes were. The function of the chloroplasts was altered compared to the control, the maximum rate of photosynthesis was lowered. The Rubisco enzyme was not activated by the substrate $\mathrm{CO}_{2}$, and thus could not function efficiently. The concentration of Rubisco proteins decreased, the concentration of carbohydrates increased, which in turn inhibited photosynthesis. According to Herbers et al. (1997) unlike the TMV MP producing transgenic plant, the PLRV MP blocks photosynthesis by another process. Based on their findings the TMV MP reduced the rate of sugar transport and allocation through the simplast in the mesophyll cells, while the PLRV MP blocks the charging of the apoplast, and the accumulating sugars take part in the extracellular signalling, which leads to the change in the expression of different genes (pathogenesis related /PR/ proteins, genes of photosynthetic proteins).

In BSMV infected barley leaves, with the increase in the concentration of RNA dependent RNA polymerase, the rRNA concentration of chloroplasts decreased (Brakke et al., 1988). This was earlier reported by Hirai and Wildman (1969) in the chloroplasts of TMV infected tobacco, which was explained by the competition between the virus and 
the chloroplast for the metabolic products. In the chloroplasts of tobacco leaves infected with TEV the synthesised total protein concentration decreased (Hampton et al., 1966).

\section{Effect of virus infection as a biotic stress factor on photosynthesis}

Stress has been described by Osmond et al. (1987) as all parameters that suppress the maximum, potential genomial value of growth and reproduction of a plant. Plants adopt to stress conditions in two ways, either by tolerance or avoidance. In the case of tolerance the plant's reaction to a moderate stress is the upregulation, while against a severe stress the downregulation of metabolic processes.

At the cellular level the damage in the membranes and the fluorescence of chlorophyll built in the thylakoid membranes indicated the post stress conditions. In the early phase of virus infection both the non-photochemical quenching of fluorescence and the predominantly reduced state of $\mathrm{Q}_{\mathrm{A}}$ the primary electronacceptor of PSII, indicated the development of symptoms and the rapid chloroplast destruction due to photoinhibitory conditions (Balachandran et al., 1997). The build up of carbohydrates and the brakeup of the equilibrium between synthesis and brakedown probably blocks the gene regulation, which effects the level of chlorophyll-protein complexes and photosynthetic metabolic enzymes.

The plant's reaction to stress was also determined by other abiotic factors, such as the light intensity or the availability of nitrogen (Balachandran et al., 1994b). TMV infection in tobacco plants has multiplied the rate of photoinhibition (which was shown in the high Fo and low Fv/Fm values) especially with low nitrogen concentrations (Balachandran and Osmond, 1994).

Similarly to the abiotic stress processes, stress hormones are also synthesised in virus infected plants. In parallel with the brakedown of chloroplasts in TMV infected tobacco plants, the concentration of abscisic acid (ABA) also rose (Fraser et al., 1986). In the leaves of healthy control plants, in which drought stress was not induced, ABA was located in the chloroplasts, while virus infection enhanced ABA synthesis, changed its location within the cell and blocked the growth (Balázs et al., 1973; Fraser and Whenham, 1989).

\section{Literature}

Allen, T. C. (1971): Subcellular responses of mesophyll cells to wild cucumber mosaic virus. Virology 47, 467-474.

Almási, A., Apatini, D., Bóka, K., Böddi, B. and Gáborjányi, R. (2000): BSMV infection inhibits chlorophyll biosynthesis in barley plants. Phys. Mol. Plant Path. 56, 227-233.

Bailiss, K. W. (1970): Infection of cucumber cotyledons by cucumber mosaic virus and the participation of chlorophyllase in the development of chlorotic lesions. Ann. Bot. 34, 647-655.

Balachandran, S., Hurry, V. M., Kelley, S. E., Osmond, C. B., Robinson, S. A., Rohozinski, J., Seaton, G. G. R. and Sims, D. A. (1997): Concepts of plant biotic stress. Some insights into the stress physiology of virus-infected plants, from the perspective of photosynthesis. Physiologia Plantarum 100, 203-213.

Balachandran, S. and Osmond, C. B. (1994): Susceptibility of tobacco leaves to photoinhibition following infection with two strains of tobacco mosaic virus under different light and nitrogen nutrition regimes. Plant Physiol. 104, 1051-1057. 
Balachandran, S., Osmond, C. B. and Makino, A. (1994a): Effects of two strains of tobacco mosaic virus on photosynthetic characteristics and nitrogen partitioning in leaves of Nicotiana tabacum cv Xanthi during photoacclimation under two nitrogen nutrition regimes. Plant Physiol. 104, 1043-1050.

Balachandran, S., Osmond, C. B. and Daley, P. F. (1994b): Diagnosis of the earliest strain-specific interactions between tobacco mosaic virus and chloroplasts of tobacco leaves in vivo by means of chlorophyll fluorescence imaging. Plant Physiol. 104, 1059-1065.

Balázs, E., Király, Z. and Gáborjányi, R. (1973): Leaf senescence and increased virus susceptibility in tobacco: The effect of abscisic acid. Physiol. Plant Path. 3, 341-346.

Banerjee, N. and Zaitlin, M. (1992): Import of tobacco mosaic virus coat protein into intact chloroplasts in vitro. Mol. Plant-Microbe Interact. 5, 466-471.

Barón, M., Rahoutei, J., Lázaro, J. J. and García-Luque, I. (1995): PSII response to biotic and abiotic stress. In: Photosynthesis: from Light to Biosphere. (Ed.: Mathis, P.), Kluwer Academic Publishers, The Netherlands. Vol. 4, 897-900.

Bedbrook, J. R. and Matthews, R. E. F. (1972): Changes in the proportions of early products of photosynthetic carbon fixation induced by TYMV infection. Virology 48, 255-258.

Bedbrook, J. R. and Matthews, R. E. F. (1973): Changes in the flow of early products of photosynthetic carbon fixation associated with the replication of TYMV. Virology 53, 84-91.

Betto, E., Bassi, M., Favali, M. A. and Conti, G. G. (1972): An electron microscopic and autoradiographic study of tobacco leaves infected with the U5 strain of tobacco mosaic virus. Phytopath. Z. 75, 193-201.

Brakke, M. K., White, J. L., Samson, R. G. and Joshi, J. (1988): Chlorophyll, chloroplast ribosomal RNA, and DNA are reduced by barley stripe mosaic virus systemic infection. Phytopathology 78, 570-574.

Carroll, T. W. (1970): Relation of barley stripe mosaic virus to plastids. Virology 42, 1015-1022.

Chalcroft, J. P. and Matthews, R. E. F. (1967): Role of virus strains and leaf ontogeny in the production of mosaic patterns by turnip yellow mosaic virus. Virology 33, 659-673.

Chua, N.-H. and Schmidt, G. W. (1978): Post-translational transport into intact chloroplasts of a precursor to the small subunit of ribulose-1,5-bisphosphate carboxylase. Proc. Natl. Acad. Sci. USA 75, 6110-6114.

Cohen, J. and Loebenstein, G. (1975): An electron microscope study of starch lesions in cucumber cotyledons infected with tobacco mosaic virus. Phytopathology 65, 32-39.

Conti, G. G., Vegetti, G., Bassi, M. and Favali, M. A. (1972): Some ultrastructural and cytochemical observations on chinese cabbage leaves infected with cauliflower mosaic virus. Virology 47, 694-700.

da Graça, J. V. and Martin, M. M. (1975): Ultrastructural changes in tobacco mosaic virus-induced local lesions in Nicotiana tabacum L. cv. "Samsun NN". Physiol. Plant Pathol. 7, 287-291.

Dawson, W. O., Bubrick, P. and Grantham, G. L. (1988): Modifications of the tobacco mosaic virus coat protein gene affecting replication, movement, and symptomatology. Phytopathology 78, 783-789.

Dhindsa, R. S., Plumb-Dhindsa, P. and Thrope, T. A. (1981): Leaf senescence: Correlated with increased levels of membrane permeability and lipid peroxidation, and decreased level of superoxide dismutase and catalase. J. Exp. Bot. 32, 93-101.

Ding, X., Shintaku, M. H., Carter, S. A. and Nelson, R. S. (1996): Invasion of minor veins of tobacco leaves inoculated with tobacco mosaic virus mutants defective in phloem-dependent movement. Proc. Natl. Acad. Sci. USA 93, 11155-11160.

Ding, X. S., Carter, S. A., Deom, C. M. and Nelson, R. S. (1998): Tobamovirus and potyvirus accumulation in minor veins of inoculated leaves from representatives of the Solanaceae and Fabaceae. Plant Physiol. $116,125-136$.

Doke, N. and Hirai, T. (1970a): Effects of tobacco mosaic virus infection on photosynthetic $\mathrm{CO}_{2}$ fixation and $\mathrm{CO}_{2}$ incorporation into protein in tobacco leaves. Virology 42, 68-77.

Doke, N. and Hirai, T. (1970b): Radioautographic studies on the photosynthetic $\mathrm{CO}_{2}$ fixation in virus-infected leaves. Phytopythology 60, 988-991.

Ehara, Y. and Misawa, T. (1975): Occurrence of abnormal chloroplasts in tobacco leaves infected systemically with the ordinary strain of cucumber mosaic virus. Phytopath. Z. 84, 233-252. 
Esau, K. (1968): Viruses in Plant Hosts. Form, Distribution and Pathogenic Effects. Madison: University of Wisconsin Press.

Fraser, R. S. S., Gerwitz, A. and Morris, G. E. L. (1986): Multiple regression analysis of the relationships between tobacco mosaic virus multiplication, the severity of mosaic symptoms, and the growth of tobacco and tomato. Physiol. Mol. Plant Pathol. 29, 239-249.

Fraser, R. S. S. and Whenham, R. J. (1989): Abscisic acid metabolism in tomato plants infected with tobacco mosaic virus: relationships with growth, symptoms and the Tm-1 gene for TMV resistance. Physiol. Mol. Plant Pathol. 34, 215-226.

Funayama, S., Hikosaka, K. and Yahara, T. (1997a): Effects of virus infection and growth irradiance on fitness components and photosynthetic properties of Eupatorium makinoi (Compositae). American J. Botany 84, 823-829.

Funayama, S., Sonoike, K. and Terashima, I. (1997b): Photosynthetic properties of leaves of Eupatorium makinoi infected by a geminivirus. Photosynthesis Research 53, 253-261.

Funayama-Noguchi, S., Sonoike, K. and Terashima, I. (1998): Effects of virus infection on photosynthesis of Eupatorium makinoi. In: Photosynthesis: Mechanisms and Effects. (Ed.: Garab, G.) Kluwer Academic Publishers, The Netherlands. Vol. 4, 2757-2760.

Gadh, I. P. S. and Hari, V. (1986): Assotiation of tobacco etch virus related RNA with chloroplasts in extracts of infected plants. Virology 150, 304-307.

Gardner, W. S. (1967): Electron microscopy of barley stripe mosaic virus: comparative cytology of tissues infected during different stages of maturity. Phytopathology 57, 1315-1326.

Goffeau, A. and Bové, J. M. (1965): Virus infection and photosynthesis. 1. Increased photophosphorylation by chloroplasts from chinese cabbage infected with turnip yellow mosaic virus. Virology 27, 243-252.

Goodman, R. N., Király, Z. and Wood, R. K. (1986): The Biochemistry and Physiology of Plant Disease. Columbia: University of Missouri Press.

Gunasinghe, U. B. and Berger, P. H. (1991): Association of potato virus Y gene products with chloroplasts in tobacco. Mol. Plant-Microbe Interact. 4, 452-457.

Hampton, R. E., Hopkins, D. L. and Nye, T. G. (1966): Biochemical effects of tobacco etch virus infection on tobacco leaf tissue. I. Protein synthesis by isolated chloroplasts. Phytochemistry 5, 1181-1185.

Hatta, T. and Matthews, R. E. F. (1974): The sequence of early cytological changes in chinese cabbage leaf cells following systemic infection with turnip yellow mosaic virus. Virology 59, 383-396.

Helms, K. and Wardlaw, I. F. (1977): Effect of temperature on symptoms of tobacco mosaic virus and movement of photosynthate in Nicotiana glutinosa. Phytopathology 67, 344-350.

Herbers, K., Tacke, E., Hazirezaei, M., Krause, K.-P., Melzer, M., Rohde, W. and Sonnewald, U. (1997): Expression of a luteoviral movement protein in transgenic plants leads to carbohydrate accumulation and reduced photosynthetic capacity in source leaves. Plant J. 12, 1045-1056.

Hibino, H., Tsuchizaki, T. and Saito, Y. (1974a): Comparative electron microscopy of cytoplasmic inclusions induced by 9 isolates of soil-borne wheat mosaic virus. Virology 57, 510-521.

Hibino, H., Tsuchizaki, T. and Saito, Y. (1974b): Electron microscopy of inclusion development in rye leaf cells infected with soil-borne wheat mosaic virus. Virology 57, 522-530.

Hirai, A. and Wildman, S. G. (1969): Effect of TMV multiplication on RNA and protein synthesis in tobacco chloroplasts. Virology 38, 73-82.

Hodgson, R. A. J., Beachy, R. N. and Pakrasi, H. B. (1989): Selective inhibition of photosystem II in spinach by tobacco mosaic virus: an effect of the viral coat protein. FEBS Lett. 245, 267-270.

Holmes, F. O. (1931): Local lesions of mosaic in Nicotiana tabacum L. Contr. Boyce Thompson Inst. 3, 163-172.

Honda, Y. and Matsui, C. (1971): Distribution of tobacco mosaic virus in etiolated tobacco leaf cells infected with two viruses. Phytopathology 61, 759-762.

Hopkins, D. L. and Hampton, R. E. (1969a): Effects of tobacco etch virus infection upon the light reactions of photosynthesis in tobacco leaf tissue. Phytopathology 59, 677-679.

Hopkins, D. L. and Hampton, R. E. (1969b): Effects of tobacco etch virus infection upon the dark reactions of photosynthesis in tobacco leaf tissue. Phytopathology 59, 1136-1140. 
Hunter, C. S. and Peat, W. E. (1973): The effect of tomato aspermy virus on photosynthesis in the young tomato plant. Physiol. Plant Pathol. 3, 512-524.

Huth, W., Lesemann, D.-E. and Paul, H.-L. (1984): Barley yellow mosaic virus: purification, electron microscopy, serology, and other properties of two types of the virus. Phytopath. Z. 111, 37-54.

Israel, H. W. and Ross, A. F. (1967): The fine structure of local lesions induced by tobacco mosaic virus in tobacco. Virology 33, 272-286.

Izadpanah, K., Huth, W., Lesemann, D.-E. and Vetten, H. J. (1993): Properties of Johnsongrass chlorotic stripe mosaic virus. J. Phytopathology 137, 105-117.

Jackson, A. O., Hunter, B. G. and Gustafson, G. D. (1989): Hordeivirus relationships and genome organization. Annu. Rev. Phytopathol. 27, 95-121.

Kano, H. (1985): Effects of light and inhibitors of photosynthesis and respiration on the multiplication of tobacco mosaic virus in tobacco protoplasts. Plant Cell Physiol. 26, 1241-1249.

Koiwa, H., Kojima, M., Ikeda, T. and Yoshida, Y. (1992): Fluctuations of particles on chloroplast thylakoid membranes in tomato plants infected with virulent or attenuated strain of tobacco mosaic virus. Ann. Phytopath. Soc. Japan 58, 58-64.

Koiwa, H., Kojima, M. and Yoshida, Y. (1989): Ultrastructural observations on chloroplasts in tomato plants infected with an attenuated strain (L11A) of tobacco mosaic virus. Ann. Phytopath. Soc. Japan 55, 41-48.

Koiwa, H., Kojima, M. and Yoshida, Y. (1990): In situ occurrence of tobacco mosaic virus aggregation in chloroplasts of infected tobacco leaves. Sci. Rep. Niigata Univ., Ser. D. (Biology) 27, 21-25.

Leal, N. and Lastra, R. (1984): Altered metabolism of tomato plants infected with tomato yellow mosaic virus. Physiol. Plant Pathol. 24, 1-7.

Lin, N.-S. and Langenberg, W. G. (1985): Peripheral vesicles in proplastids of barley stripe mosaic virusinfected wheat cells contain double-stranded RNA. Virology 142, 291-298.

Lindbeck, A. G. C., Dawson, W. O. and Thomson, W. W. (1991): Coat protein-related polypeptides from in vitro tobacco mosaic virus coat protein mutants do not accumulate in the chloroplasts of directly inoculated leaves. Mol. Plant-Microbe Interact. 4, 89-94.

Lucas, W. J., Olesinski, A., Hull, R. J., Haudenshield, J. S., Deom, C. M., Beachy, R. N. and Wolf, S. (1993): Influence of the tobacco mosaic virus $30-\mathrm{kDa}$ movement protein on carbon metabolism and photosynthate partitioning in transgenic tobacco plants. Planta 190, 88-96.

Magyarosy, D. C., Duchanan, B. B. and Schürmann, P. (1973): Effect of a systemic virus infection on chloroplast function and structure. Virology 55, 426-438.

Mandahar, C. L. and Garg, I. D. (1972): Effect of cucumber mosaic virus on chlorophyll content, photosynthesis, respiration and carbohydrates of infected Luffa aegyptiaca mill. Phytopath. Z. 75, 181-186.

Masuta, C., Suzuki, M., Matsuzaki, T., Honda, I., Kuwata, S., Takanami, Y. and Koiwai, A. (1993): Bright yellow chlorosis by cucumber mosaic virus Y satellite RNA is specifically induced without severe chloroplast damage. Physiol. Mol. Plant Pathol. 42, 267-278.

Matthews, R. E. F. (1977): Tymovirus Group. The Atlas of Insect and Plant Viruses. Academic Press, London.

Mayhew, D. E. and Ford, R. E. (1974): Detection of ribonuclease-resistant RNA in chloroplasts of corn leaf tissue infected with maize dwarf mosaic virus. Virology 57, 503-509.

Mc Kinney, H. H. and Greeley, L. W. (1965): Biological characteristics of barley stripe mosaic virus strains and their evolution. Tech. Bull. U. S. Dept. Agr. 1324.

Mc Mullen, C. R., Gardner, W. S. and Myers, G. A. (1978): Aberrant plastids in barley leaf tissue infected with barley stripe mosaic virus. Phytopathology 68, 317-325.

Mohamed, N. A. (1973): Some effects of systemic infection by tomato spotted wilt virus on chloroplasts of Nicotiana tabacum leaves. Physiol. Plant Pathol. 3, 509-516.

Mohamed, N. A. and Randles, J. W. (1972): Effect of tomato spotted wilt virus on ribosomes, ribonucleic acids and fraction I protein in Nicotiana tabacum leaves. Physiol. Plant Pathol. 2, 235-245.

Naderi, M. and Berger, P. H. (1997): Effects of chloroplasts targeted potato virus Y coat protein on transgenic plants. Physiol. Mol. Plant Pathol. 50, 67-83. 
Naidu, R. A., Krishnan, M., Nayudu, M. V. and Gnanam, A. (1984a): Studies on peanut green mosaic virus infected peanut (Arachis hypogaea L.) leaves. II. Chlorophyll-protein complexes and polypeptide composition of thylakoid membranes. Physiol. Plant Pathol. 25, 191-198.

Naidu, R. A., Krishnan, M., Nayudu, M. V. and Gnanam, A. (1986): Studies on peanut green mosaic virus infected peanut (Arachis hypogaea L.) leaves. III. Changes in the polypeptides of photosystem II particles. Physiol. Mol. Plant Pathol. 29, 53-58.

Naidu, R. A., Krishnan, M., Ramanujam, P., Gnanam, A. and Nayudu, M. V. (1984b): Studies on peanut green mosaic virus infected peanut (Arachis hypogaea L.) leaves. I. Photosynthesis and photochemical reactions. Physiol. Plant Pathol. 25, 181-190.

Olesinski, A. A., Lucas, W. J., Galun, E. and Wolf, S. (1995): Pleiotropic effects of tobacco mosaic virus movement protein on carbon metabolism in transgenic tobacco plants. Planta 197, 118-126.

Osmond, C. B., Austin, M. P., Berry, J. A., Billings, W. D., Boyer, J. S., Dacey, J. W. H., Nobel, P. S., Smith, S. D. and Winner, W. E. (1987): Stress physiology and the distribution of plants. BioScience 37, 38-48.

Osmond, C. B., Daley, P. F., Badger, M. R. and Lüttge, U. (1998): Chlorophyll fluorescence quenching during photosynthetic induction in leaves of Abutilon striatum Dicks. infected with abutilon mosaic virus, observed with a field-portable imaging system. Bot. Acta 111, 390-397.

Peterson, R. B. and Aylor, D. E. (1995): Chlorophyll fluorescence induction in leaves of Phaseolus vulgaris infected with bean rust (Uromyces appendiculatus). Plant Physiol. 108, 163-171.

Platt, S. G., Henriques, F. and Rand, L. (1979): Effects of virus infection on the chlorophyll content, photosynthetic rate and carbon metabolism of Tolmiea menziesii. Physiol. Plant Pathol. 16, 351-365.

Pratt, M. J. (1969): The incidence of tobacco mosaic virus in plastids of etiolated tobacco leaves. Virology 39, 344-346.

Rahoutei, J., García-Luque, I., Cremona, V. and Barón, M. (1998): Effect of tobamovirus infection on PSII complex on infected plants. In: Photosynthesis: Mechanisms and Effects. (Ed.: Garab, G.) Kluwer Academic Publishers, The Netherlands. Vol. 4, 2761-2764.

Ralph, R. K., Bullivant, S. and Wojcik, S. J. (1971): Evidence for the intracellular site of double-stranded turnip yellow mosaic virus RNA. Virology 44, 473-479.

Rana, G. L., Piazzolla, P., Lafortezza, R. and Greco, N. (1989): Characterization of a latent elongated virus from globe artichoke (Cynara scolymus L.) in Italy. J. Phytopathol. 125, 289-298.

Reinero, A. and Beachy, R. N. (1986): Association of TMV coat protein with chloroplast membranes in virusinfected leaves. Plant Mol. Biol. 6, 291-301.

Reinero, A. and Beachy, R. N. (1989): Reduced Photosystem II activity and accumulation of viral coat protein in chloroplasts of leaves infected with tobacco mosaic virus. Plant Physiol. 89, 111-116.

Roberts, P. L. and Wood, K. L. (1981): Comparison of protein synthesis in tobacco systemically infected with a severe or a mild strain of cucumber mosaic virus. Phytopath. Z. 102, 257-265.

Roberts, P. L. and Wood, K. R. (1982): Effects of a severe (P6) and a mild (W) strain of cucumber mosaic virus on tobacco leaf chlorophyll, starch and cell ultrastructure. Physiol. Plant Pathol. 21, 31-37.

Russo, M. and Martelli, G. P. (1981): Ultrastructure of turnip crinkle- and saguaro cactus virus-infected tissues. Virology 118, 109-116.

Šarič, A. and Wrischer, M. (1975): Fine structure changes in different host plants induced by grapevine fanleaf virus. Phytopath. Z. 84, 97-104.

Schoelz, J. E. and Zaitlin, M. (1989): Tobacco mosaic virus RNA enters chloroplasts in vivo. Proc. Natl. Acad. Sci. USA 86, 4496-4500.

Schuchalter-Eicke, G. and Jeske, H. (1983): Seasonal changes in the chloroplast ultrastructure in Abutilon mosaic virus (AbMV) infected Abutilon spec. (Malvaceae). Phytopath. Z. 108, 172-184.

Shalla, T. A., Petersen, L. J. and Giunchedi, L. (1975): Partial characterization of virus-like particles in chloroplasts of plants infected with the U5 strain of TMV. Virology 66, 94-105.

Shukla, P. and Hiruki, C. (1975): Ultrastructural changes in leaf cells of Chenopodium quinoa infected with potato virus S. Physiol. Plant Pathol. 7, 189-194. 
Sjolund, R. D. and Smith, D. D. (1974): Freeze-fracture studies of photosynthetically deficient "supergranal" chloroplasts in tissue cultures containing virus-like particles. J. Cell Biol. 60, 285-292.

Spencer, D. F. and Kimmins, W. C. (1971): Ultrastructure of tobacco mosaic virus lesions and surrounding tissue in Phaseolus vulgaris var. Pinto. Canad. J. Bot. 49, 417-421.

Sutherland, M. W. (1991): The generation of oxygen radicals during host plant responses to infection. Physiol. Plant Pathol. 39, 79-93.

Takahashi, H. and Ehara, Y. (1992): Changes in the activity and the polypeptide composition of the oxygeneevolving complex in photosystem II of tobacco leaves infected with cucumber mosaic virus strain Y. Mol. Plant-Microbe Interact. 5, 269-272.

Takahashi, H., Ehara, Y. and Hirano, H. (1991): A protein in the oxygen-evolving complex in the chloroplast is associated with symptom expression on tobacco leaves infected with cucumber mosaic virus strain Y. Plant Mol. Biol. 16, 689-698.

Teakle, D. S. and Pares, R. D. (1977): Potyvirus (Potato Virus Y) Group. The Atlas of Insect and Plant Viruses. Academic Press, London.

Técsi, L. I., Maule, A. J., Smith, A. M. and Leegood, R. C. (1994): Complex, localized changes in $\mathrm{CO}_{2}$ assimilation and starch content associated with the susceptible interaction between cucumber mosaic virus and a cucurbit host. The Plant Journal 5, 837-847.

Técsi, L. I., Smith, A. M., Maule, A. J. and Leegood, R. C. (1996): A spatial analysis of physiological changes associated with infection of cotyledons of marrow plants with cucumber mosaic virus. Plant Physiol. 111, 975-985.

Técsi, L. I., Wang, D., Smith, A. M., Leegood, R. C. and Maule, A. J. (1992): Red clover mottle virus infection affects sink-source relationships and starch accumulation in pea plants. J. Exp. Bot. 43, 1409-1412.

Tomlinson, J. A. and Webb, M. J. (1977): Ultrastructural changes in chloroplasts of lettuce infected with beet western yellows virus. Physiol. Plant Pathol. 12, 13-18.

Tu, J. C. (1978): Alterations in chloroplast and cell membranes associated with cAMP-induced dissociation of starch grains in clover yellow mosaic virus infected clover. Canad. J. Bot. 57, 360-369.

Tu, J. C., Ford, R. E. and Krass, C. J. (1967): Comparison of chloroplasts in maize dwarf mosaic virus-infected and healthy corn, sorghum, and Johnson grass. Phytopathology 57, 834.

Ushiyama, R. and Matthews, R. E. F. (1970): The significance of chloroplast abnormalities associated with infection by turnip yellow mosaic virus. Virology 42, 293-303.

Weintraub, M. and Ragetli, H. W. J. (1964): An electron microscope study of tobacco mosaic virus lesions in Nicotiana glutinosa L. J. Cell. Biol. 23, 499-509.

Weststeijn, E. A. (1978): Permeability changes in the hypersensitive reaction of Nicotiana tabacum cv. Xanthi nc. after infection with tobacco mosaic virus. Physiol. Plant Pathol. 13, 253-258.

White, J. L. and Brakke, M. K. (1983): Protein changes in wheat infected with wheat streak mosaic virus and in barley infected with barley stripe mosaic virus. Physiol. Plant Pathol. 22, 87-100.

Wolf, S. and Millatiner, A. (2000): Effect of tobacco mosaic virus movement protein on photosynthesis in transgenic tobacco plants. J. Plant Physiol. 156, 253-258.

Zaitlin, M. and Hull, R. (1987): Plant virus-host interactions. Ann. Rev. Plant Physiol. 38, 291-315.

Ziemieczki, A. and Wood, K. R. (1975): Changes in the soluble protein constitution of cucumber cotyledons following infection with two strains of cucumber mosaic virus. Physiol. Plant Pathol. 7, 79-89. 